\title{
Correlation between the expression of hTERT gene and the clinicopathological characteristics of hepatocellular carcinoma
}

\author{
XU ZHOU, JUN LU and HUAQIANG ZHU \\ Department of General Surgery, Shandong Provincial Hospital Affiliated to Shandong University, \\ Jinan, Shandong 250014, P.R. China
}

Received August 26, 2014; Accepted May 8, 2015

DOI: $10.3892 / \mathrm{ol} .2015 .3892$

\begin{abstract}
The aim of the present study was to detect the expression levels of the human telomerase reverse transcriptase (hTERT) gene in hepatocellular carcinoma (HCC), and investigate its significance in the incidence and development of the cancer. HCC tissues and corresponding para-carcinoma liver tissues were surgically collected from 78 patients with HCC who presented to Shandong Provincial Hospital (Jinan, Shandong, China). hTERT expression at the protein and mRNA levels were detected by immunohistochemistry (streptavidin peroxidase method) and reverse transcription polymerase chain reaction, respectively, in the HCC tissues and corresponding para-carcinoma liver tissues of $78 \mathrm{HCC}$ patients and in 12 samples of normal liver tissue. The data were analyzed using SPSS 17.0 statistical software, and employing $\chi^{2}$ tests and t-tests. hTERT protein was mainly expressed in the HCC cell cytoplasm, but was occasionally observed in the cell nucleus. The positive rates of hTERT protein and mRNA expression in the HCC patients were $84.62 \%(66 / 78)$ and $78.21 \%(61 / 78)$, respectively, which was significantly higher compared with the rates of $10.26 \%(8 / 78)$ and $8.97 \%(7 / 78)$ in the paired para-carcinoma liver tissues $(\mathrm{P}<0.01)$. hTERT protein and mRNA were not expressed in the normal liver tissues $(0 / 12) \cdot \chi^{2}$ test and t-test analysis revealed that hTERT gene expression was correlated with tumor grade, the presence/absence of a portal vein tumor thrombus, hepatitis B surface antigen positivity and a high $\alpha$-fetoprotein level $(\mathrm{P}<0.05)$ rather than patient age, gender or tumor size. Expression of the hTERT gene may play a pivotal role in the incidence and development of HCC. The hTERT gene potentially serves as an important molecular and biological index for diagnosing and predicating the biological behavior of HCC.
\end{abstract}

Correspondence to: Dr Huaqiang Zhu, Department of General Surgery, Shandong Provincial Hospital Affiliated to Shandong University, 9677 Jingshi Road, Jinan, Shandong 250014, P.R. China E-mail: zhuhuaqiang163@163.com

Key words: human telomerase reverse transcriptase, hepatocellular carcinoma, gene expression

\section{Introduction}

Hepatocellular carcinoma (HCC) is one of the most common malignant tumors (1). In the USA, between 1992 and 2005, the overall incidence rate of the disease increased from 3.1 to 5.4 cases per 100,000 individuals (2). Furthermore, during the same period, the mortality rate of HCC increased from 3.3 to 4.0 mortalities per 100,000 individuals (2). However, as a result of advances in HCC treatment, the one-year survival rate of HCC following diagnosis increased from 25 to $47 \%$ between 1975 and 2005 in the USA (2). The typical features of HCC include yellow skin, abdominal bloating and bruising easily as a result of blood clotting abnormalities, as well as other non-specific symptoms, such as loss of appetite, unintentional weight loss, abdominal pain, nausea, vomiting and fatigue (3). At present, HCC is usually diagnosed by dynamic contrast-enhanced magnetic resonance imaging or computed tomography (4). High levels of $\alpha$-fetoprotein $(\sim 400 \mathrm{ng} / \mu \mathrm{l})$ may also be a predictor of HCC in patients exhibiting liver lesions (1-2 cm in diameter) on imaging examination (4).

HCC develops as a result of cellular mutations, which lead to increased levels of cell replication. Ultimately, the increased replication rate results in cells avoiding apoptosis. Chronic hepatitis $\mathrm{B}$ and/or $\mathrm{C}$ infections may accelerate the progression of HCC by repeatedly activating the body's own immune system to attack liver cells (5).

The clinical prognosis of HCC is relatively poor as only $\sim 10-20 \%$ of HCC lesions may be completely resected. If the cancerous tissue cannot be removed completely, the survival time of HCC patients is usually 3-6 months (2). The prognosis of HCC is poor as the majority of patients present at an advanced stage of disease and at present, medical expertise and facilities remain insufficient.

Recent studies proved that the activation of telomerase and its upregulated activity serve as an extremely pivotal step in the mechanism of HCC (6-8). The activity levels of telomerase mainly rely upon the expression level of human telomerase reverse transcriptase (hTERT). In HCC patients, the activation of telomerase and a high expression level of the hTERT subunit catalyzed by telomerase have been reported (1,9-11). Furthermore, hTERT expression and telomerase activation has been identified in $\leq 90 \%$ of human malignant tumors, including gastric, brain and renal cancers (12). High hTERT expression has been found to correlate with advanced disease 
Table I. Expression of hTERT protein and mRNA in hepatocellular carcinoma and para-carcinoma tissues.

\begin{tabular}{|c|c|c|c|c|c|c|c|}
\hline Specimen & $\mathrm{n}$ & $\begin{array}{l}\text { hTERT protein expression, } \\
\mathrm{n} \text { (positive rate) }\end{array}$ & $\chi^{2}$ & P-value & $\begin{array}{l}\text { hTERT mRNA expression, } \\
\text { n (positive rate) }\end{array}$ & $\chi^{2}$ & P-value \\
\hline Liver cancer tissues & 78 & $66(84.62)$ & \multirow{2}{*}{76.74} & \multirow{2}{*}{$<0.01$} & $61(78.21)$ & \multirow{2}{*}{74.21} & \multirow{2}{*}{$<0.01$} \\
\hline Para-carcinoma tissues & 78 & $8(10.26)$ & & & $7(8.97)$ & & \\
\hline
\end{tabular}

hTERT, human telomerase reverse transcriptase.

and unfavorable prognoses in various malignancies (13). However, opinions vary significantly on aspects such as the simultaneous detection of the hTERT protein and gene, its correlation with clinicopathological characteristics and whether hTERT is expressed in para-carcinoma and normal liver tissues. Consequently, the role of hTERT in the incidence of HCC should be further investigated. In the present study, immunohistochemical tests (streptavidin peroxidase method) and reverse transcription-polymerase chain reaction (RT-PCR) were employed to simultaneously detect the expression levels of hTERT protein and mRNA in HCC, corresponding para-carcinoma and normal liver tissues qualitatively and quantitatively, aiming to investigate their significance and effects in the incidence of HCC.

\section{Subjects and methods}

Study subjects. HCC tissues and corresponding para-carcinoma liver tissues were surgically collected from 78 patients with HCC who presented to Shandong Provincial Hospital (Jinan, Shandong, China). The HCC tissues were kept as fresh specimens and corresponding para-carcinoma liver tissues were embedded in paraffin for further analysis. The para-carcinoma liver tissues were collected from $>3 \mathrm{~cm}$ away from the tumor margin. Among the participants, 54 were male and 24 female, with a male:female ratio of 2.25:1. The age range was $27-78$ years, with a mean age of 51 years. All patients were diagnosed with HCC by pathological examination, and did not undergo pre-operative radiotherapy or chemotherapy. The clinical and pathological data were complete. Normal liver tissues were collected from 12 patients; 8 samples from patients receiving liver surgery and 4 samples from those undergoing hepatic hemangioma excision, distant from the liver lesions. All samples were confirmed to be normal liver tissues by pathological methods and hepatitis B surface antigen ( $\mathrm{HBsAg}$ ) was negative in the serum. For the specimens used for mRNA detection, necrotic tissues and blood clots were immediately removed after surgery, and the tissues were frozen in liquid nitrogen $\left(-80^{\circ} \mathrm{C}\right)$ within $30 \mathrm{~min}$. The samples prepared for subsequent immunochemical tests were subject to formaldehyde fixation, dehydration, conventional paraffin embedding and sectioning to a thickness of $4 \mu \mathrm{m}$. The samples were finally diagnosed and graded by physicians from the Department of Pathology (Shandong Provincial Hospital). Ethical approval was obtained from the Medical Ethics Committee of Shandong Provincial Hospital Affiliated to Shandong University. In addition, written informed consent was obtained from all patients.
Materials and reagents. Anti-hTERT rabbit polyclonal antibody S-P reagent kits (1:100 dilution) were purchased from Zymed Life Technologies (Carlsbad, CA, USA). The confirmed positive tissue sections were utilized as positive controls and the primary antibody was replaced by phosphate-buffered saline in the negative controls.

Immunohistochemical tests. During the immunohistochemical test, $4-\mu \mathrm{m}$ paraffin sections were dewaxed at $65^{\circ} \mathrm{C}$ and treated with $3 \%$ hydrogen peroxide for endogenous peroxidase inactivation for $5 \mathrm{~min}$ prior to microwave antigen retrieval. Supplementary primary antibody was added for overnight incubation at $4^{\circ} \mathrm{C}$, followed by incubation with biotin-labeled secondary antibody at $37^{\circ} \mathrm{C}$ for $30 \mathrm{~min}$ and streptavidin-labeled horseradish peroxide enzyme at $37^{\circ} \mathrm{C}$ for $30 \mathrm{~min}$. The cells were visualized with diaminobenzidine under a light microscope after the slides had been irrigated, double stained with hematoxylin and covered with a cover slip. Positive cells presented with yellow-brownish particles within cytoplasm. The sections were evaluated by two experienced physicians from the Department of Pathology, who were blinded to the study. Next, the sections were graded by a half-quantitative method: 0 points, $<25 \%$ positive target cells; 1 point, $25-50 \%$; 2 points, $51-57 \%$; and 3 points, $>75 \%$. Color visualization was evaluated and graded by the presence of color or not and the following color scale: 0 points, no cellular staining; 1 point, light yellow-brownish; 2 points, yellow-brownish; and 3 points, brown. The final score was calculated from the sum of the two scores: A score of $<2$ was deemed as (-), while a score of 2-3 was defined as $(+), 4-5$ as $(++)$ and $\geq 6$ as $(+++)$.

\section{RT-PCR}

Extraction of total RNA. The experimental procedures were conducted strictly according to the manufacturer's instructions. Briefly, total RNA was extracted from cells using an Invitrogen Trizol RNA extraction kit (Thermo Fisher Scientific, Inc., Waltham, MA, USA). A total of $1 \mathrm{ml}$ Trizol was used for each sample. The first-strand cDNA was synthesized from 500 ng total RNA using an iScript cDNA synthesis kit (Bio-Rad Laboratories, Inc., Hercules, CA, USA). Quantitative PCR was performed using an icycler $\mathrm{iQ}^{\mathrm{TM}}$ system (Bio-Rad Laboratories, Inc.) and the TaqMan-iQ ${ }^{\mathrm{TM}}$ Supermix kit (BioRad Laboratories, Inc.). The conditions for RT-PCR are: denaturation at $94^{\circ} \mathrm{C}$ for $50 \mathrm{sec}$, annealing at $58^{\circ} \mathrm{C}$ for $45 \mathrm{sec}$ and extension at $72^{\circ} \mathrm{C}$, for a total of 30 cycles.

$c D N A$ synthesis. The total volume of the reaction system was $25 \mu 1$, supplemented with $5 \mu 1$ 5X RT buffer, $5 \mu 1 \mathrm{dNTP}, 0.5 \mu \mathrm{l}$ 
Table II. Association between clinicopathological characteristics and hTERT protein and mRNA expression in hepatocellular carcinoma tissues.

\begin{tabular}{|c|c|c|c|c|}
\hline Pathological indices & $\begin{array}{l}\text { Number of } \\
\text { cases }\end{array}$ & $\begin{array}{l}\text { Positive expression rate } \\
\text { of hTERT protein }(\%)\end{array}$ & $\begin{array}{c}\text { Expression level of } \\
\text { hTERT mRNA (mean } \pm \text { SD) }\end{array}$ & P-value \\
\hline Gender & & & & $>0.05$ \\
\hline Male & 54 & 88.71 & $1.551 \pm 0.020$ & \\
\hline Female & 24 & 88.69 & $1.539 \pm 0.016$ & \\
\hline Age, years & & & & $>0.05$ \\
\hline$\leq 50$ & 31 & 86.36 & $1.38 \pm 0.013$ & \\
\hline$>50$ & 47 & 85.71 & $1.575 \pm 0.020$ & \\
\hline Tumor size, cm & & & & $>0.05$ \\
\hline$<5$ & 19 & 80.07 & $1.534 \pm 0.027$ & \\
\hline$\geq 5$ & 59 & 82.04 & $1.571 \pm 0.021$ & \\
\hline Edmondson classification & & & & $<0.05$ \\
\hline I-II & 33 & $76.04^{\mathrm{a}}$ & $1.501 \pm 0.027^{\mathrm{a}}$ & \\
\hline III-IV & 45 & 96.01 & $1.564 \pm 0.012$ & \\
\hline Degree of differentiation & & & & $<0.05$ \\
\hline Good & 26 & $78.05^{\mathrm{a}}$ & $1.531 \pm 0.012^{\mathrm{a}}$ & \\
\hline Poor & 52 & 95.96 & $1.595 \pm 0.025$ & \\
\hline Portal vein tumor thrombus & & & & $<0.05$ \\
\hline Yes & 30 & $77.78^{\mathrm{a}}$ & $1.573 \pm 0.016^{\mathrm{a}}$ & \\
\hline No & 48 & 95.99 & $1.504 \pm 0.026$ & \\
\hline $\mathrm{AFP}, \mu \mathrm{g} / 1$ & & & & $<0.05$ \\
\hline$<400$ & 25 & $72.22^{\mathrm{a}}$ & $1.537 \pm 0.013^{\mathrm{a}}$ & \\
\hline$>400$ & 53 & 93.18 & $1.574 \pm 0.024$ & \\
\hline HbsAg & & & & $<0.01$ \\
\hline Negative & 20 & $61.54^{\mathrm{b}}$ & $1.501 \pm 0.017^{b}$ & \\
\hline Positive & 58 & 97.96 & $1.579 \pm 0.025$ & \\
\hline
\end{tabular}

${ }^{a} \mathrm{P}<0.05$ and ${ }^{\mathrm{b}} \mathrm{P}<0.01$, comparison between two groups using the same pathological parameters. hTERT, human telomerase reverse transcriptase; SD, standard deviation; AFP, $\alpha$-fetoprotein; HBsAg, hepatitis B surface antigen.

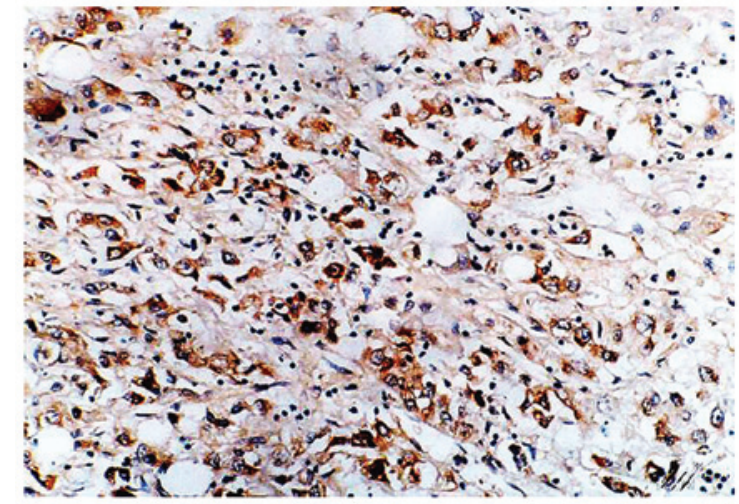

Figure 1. Strong positive expression of human telomerase reverse transcriptase protein and DNA visualization in hepatocellular carcinoma tissues (magnification, $\mathrm{x} 400$ ).

RNA template, $5 \mu$ l random primer [oligo(dT)], $1 \mu 1$ reverse transcriptase M-MLV, $0.5 \mu 1$ RNAase inhibitor RNasin and $10.5 \mu \mathrm{l}$ water free from RNase. Denaturation was performed at $42^{\circ} \mathrm{C}$ for $60 \mathrm{~min}$ and annealing at $95^{\circ} \mathrm{C}$ for $5 \mathrm{~min}$.
PCR amplification and quantitative analysis. The primers for hTERT and internal standard GAPDH were designed as follows using Genefisher software (Bielefeld University, Bielefeld, Germany): hTERT forward, 5'-TTTCTGGAGCTGCTTGGGAA-3' and reverse, 5'-GAA GAGCCTGAGCAGCTCGA-3' (44-bp product); and GAPDH forward, 5'-TCCTCTGACTTCAACAGCGACACC-3' and reverse, 5'-TCTCTCTTCCTCTTGTCGTCTTGG-3' (286-bp product). With regard to the amplification system, $5.0 \mu \mathrm{l}$ 10X PCR buffer, $4.0 \mu \mathrm{l} \mathrm{MgO}, 2 \mu \mathrm{l} \mathrm{dNTP}, 2 \mu \mathrm{l} \mathrm{cDNA}, 1 \mu \mathrm{l}$ of each primer $(1 \mathrm{mmol} / \mathrm{l})$ and $2 \mu \mathrm{l}$ Taq DNA polymerase were used and adjusted to $50 \mu \mathrm{l}$ by adding double distilled water. For the amplification conditions, hTERT was subjected to denaturation at $94^{\circ} \mathrm{C}$ for $50 \mathrm{sec}$, annealing at $58^{\circ} \mathrm{C}$ for $45 \mathrm{sec}$ and extension at $72^{\circ} \mathrm{C}$, for a total of 30 cycles. GAPDH underwent denaturation at $94^{\circ} \mathrm{C}$ for $30 \mathrm{sec}$, annealing at $56^{\circ} \mathrm{C}$ for $30 \mathrm{sec}$ and extension at $72^{\circ} \mathrm{C}$, for 26 cycles in total. The PCR amplification products were subjected to electrophoresis on $1.5 \%$ agarose gels and then images were captured by utilizing the GDS8000 Gel Documentation System (UVP Inc., Upland, CA, USA). 


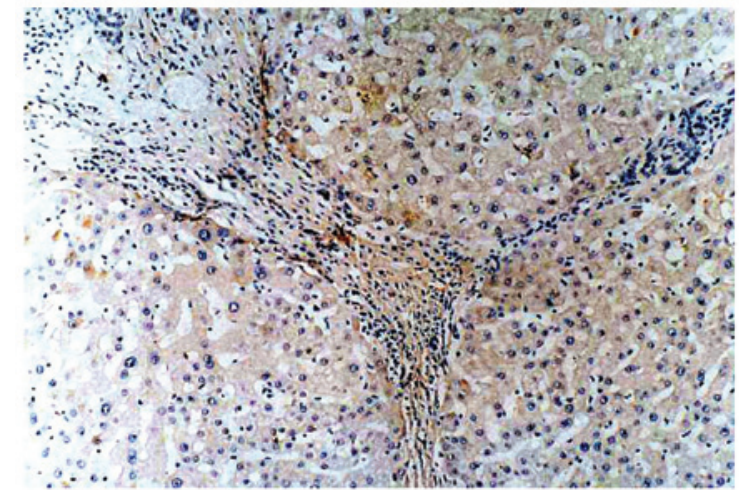

Figure 2. Weak positive expression of human telomerase reverse transcriptase protein and DNA visualization in atypical para-carcinoma hyperplasia tissues (magnification, x100).

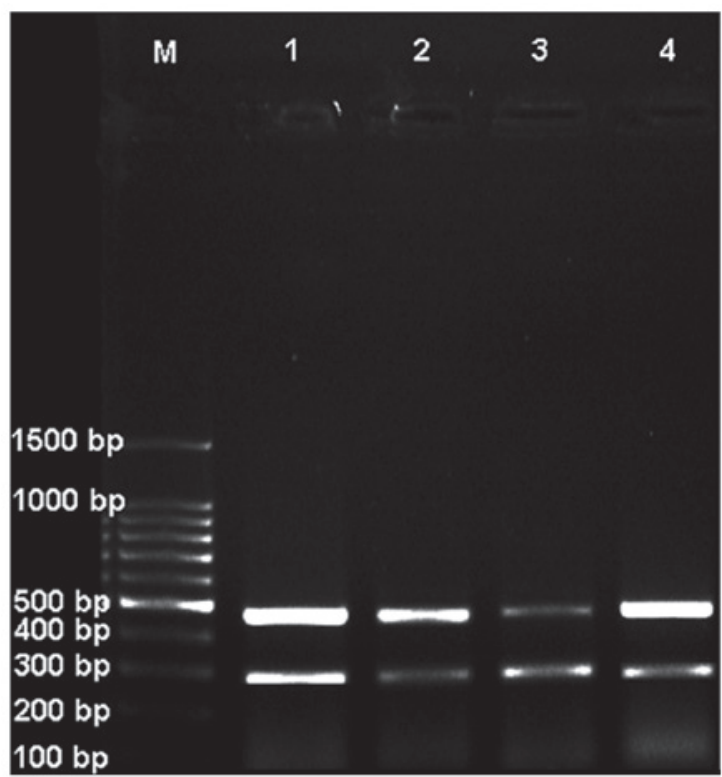

Figure 3. Association between clinicopathological parameters and expression level of hTERT mRNA in HCC tissues. Lanes: M, DNA marker; 1, AFP $>400 \mu \mathrm{g} / 1$, expression level of hTERT mRNA in HCC; 2 , AFP $<400 \mu \mathrm{g} / 1$, expression level of hTERT mRNA in $\mathrm{HCC}$; $3, \mathrm{HBsAg}(+)$, expression level of hTERT mRNA in HCC; 4, HBsAg(-), expression level of hTERT mRNA in HCC. Comparison between lanes 2 and $3, \mathrm{P}<0.05$; comparison between lanes 4 and $5, \mathrm{P}<0.01$. GAPDH was used as an internal standard. hTERT, human telomerase reverse transcriptase; HCC, hepatocellular carcinoma.

Statistical analysis. The data were analyzed using SPSS 17.0 statistical software (SPSS, Inc., Chicago, IL, USA) and employed $\chi^{2}$ tests and t-tests. $\mathrm{P}<0.05$ was considered to indicate a statistically significant difference.

\section{Results}

Expression of hTERT protein in HCC and para-carcinoma tissues. Positive expression of hTERT protein was mainly observed within the cytoplasm, displayed as yellow-brownish particles or lamellae staining in the cytoplasm, but was occasionally also observed in the nucleus. The positive cells were distributed in a diffuse or dispersed pattern. Positive hTERT protein expression was observed in 66 out of the $78 \mathrm{HCC}$ tissues (positive rate, $84.62 \%$; Fig. 1) and in 8 out of the
78 para-carcinoma tissues (positive rate, 10.26\%). The positive rates significantly differed between the two groups $(\mathrm{P}<0.01)$, as illustrated in Table I. Among the 78 HCC samples, 36 were graded as (+++), 20 as (++), 10 as (+) and 12 as (-). For the 78 corresponding para-carcinoma tissues, positive signals were observed in the atypical proliferative liver cells of 8 samples (Fig. 2), 1 of which showed weak positive expression (+) and 2 of which exhibited weak or moderate expression $(++)$ in the hepatic portal area or few mononuclear cells among fibrous tissues. No positive expression was observed in the 12 normal liver samples and the negative controls.

Expression of hTERT mRNA in HCC and para-carcinoma tissues. As shown in Fig. 1, the positive rate of hTERT mRNA expression was $78.21 \%(61 / 78)$ in the HCC tissues and $8.97 \%(7 / 78)$ in the para-carcinoma tissues. Statistical significance was observed between the HCC and para-carcinoma tissues regarding the positive rate of hTERT mRNA expression $(\mathrm{P}<0.01)$. No hTERT mRNA expression was detected in the normal hepatic tissues.

Association between hTERT gene expression and the clinicopathological characteristics of HCC. All patients were grouped according to gender, age, size of primary tumor, degree of differentiation, the presence of portal venous tumor thrombosis, serum $\alpha$-fetoprotein (AFP) level and the presence of HBsAg. The expression levels of hTERT mRNA were qualitatively and quantitatively compared. As illustrated in Table II, and Fig. 3, positive hTERT protein expression at the translational level and the relative value of hTERT mRNA expression at the transcriptional level were not correlated with age, gender or tumor size $(\mathrm{P}>0.05)$. The expression level of HCC samples of Edmondson grades I and II (14) were significantly higher compared with those of Edmondson grades III and IV $(\mathrm{P}<0.05)$, which were associated with the presence of portal venous tumor thrombosis $(\mathrm{P}<0.05)$, the level of serum AFP $(\mathrm{P}<0.05)$ and the presence of HBsAg $(\mathrm{P}<0.01)$.

\section{Discussion}

Similar to other malignant tumors, HCC possesses the vital biological characteristic of cell immortality, which is acquired mainly from the activation and upregulation of telomerase. hTERT is a pivotal protein component involved in the regulation of telomerase. hTERT gene expression complies with the expression of telomerase activity, which is of great significance for maintaining the length of chromosome telomeres, preserving unlimited cell reproduction and proliferation (15-18). The present study simultaneously detected the expression levels of the hTERT gene in HCC, para-carcinoma and normal liver tissues from quantitative, qualitative and localization perspectives. In particular, the association between hTERT gene expression and the clinicopathological parameters of HCC tissues were analyzed, which provided a solid foundation to assess the effect of hTERT in the incidence and development of HCC. To properly prevent the incidence of RNA degradation during sample collection and the experimental procedures, and to minimize the errors resulting from tissue weight differences and operational errors, the $\mathrm{Ct}$ ratio between hTERT and GAPDG mRNA reverse transcription 
amplification products with stable expression was utilized to evaluate the expression level of hTERT.

Compared with the 62 para-carcinoma tissue samples, the expression levels of the hTERT gene in the HCC tissues was significantly enhanced at the translational and transcriptional levels (both $\mathrm{P}<0.01$ ), indicating the high positive expression of the hTERT gene in HCC tissues. The positive expression rates of hTERT protein and mRNA were 84.62 and $78.21 \%$ in the HCC tissues, which was consistent with the rates of 87.68 and $84.02 \%$ reported by Toshikuni et al (19), indicating that the high expression of the hTERT gene may be essential in the incidence and progression of HCC.

The findings in the present study further confirm that hTERT gene expression is not correlated with patient age, gender or tumor size $(\mathrm{P}<0.05)$, whereas positive expression is gradually enhanced with the decreased differentiation degree of HCC, with statistical significance $(\mathrm{P}<0.05)$, which is consistent with the fidnings of previous studies $(1,9,10)$. The quantitative analysis of hTERT activity revealed that the expression level of HCC of Edmondson grades III and IV was $1.54 \pm 0.012$, which was significantly higher compared with the value of $1.501 \pm 0.027$ for Edmondson grades I and II $(\mathrm{P}<0.05)$, suggesting that hTERT gene expression is correlated with the differentiation of HCC. The expression level of hTERT mRNA was $1.75 \pm 0.26$ in the patients with portal venous tumor thrombosis, with a significant difference $(\mathrm{P}<0.05)$, indicating that the hTERT gene is probably associated with the invasion and metastasis of HCC.

Additionally, when using an AFP level of $400 \mu \mathrm{g} / \mathrm{l}$ as a standard, the expression of the hTERT gene in the HCC tissues positive for AFP was significantly higher than that in those negative for AFP $(\mathrm{P}<0.05)$. The expression level of hTERT mRNA in the HCC patients with HBV infection (presence of HBsAg) was $1.579 \pm 0.025$, which was significantly higher than the level of $0.501 \pm 0.017$ in the HBsAg-negative HCC group $(\mathrm{P}<0.01)$. These outcomes indicate that certain effective components corresponding to HBV interact with hTERT mRNA, and the potential role of these two factors in the incidence of HCC and the underlying regulatory mechanism will be the focus of our future investigations.

Taken together, the present results showed that the activation and expression of hTERT was closely correlated with HCC, with an extremely vital role in the incidence and progress of $\mathrm{HCC}$ and the invasion and metastasis of tumors. hTERT is a promising evaluation marker for the diagnosis, malignant progress and prognosis of HCC, serving as an ideal target for the gene therapy of the cancer.

\section{Acknowledgements}

This study was supported by the Natural Science Foundation of Shandong Province, China (grant no. Y2008C22) and the Excellent Youth Scientist Foundation of Shandong Province, China (grant no. 2007BS03038).

\section{References}

1. Iliopoulos D, Satra M, Drakaki A, Poultsides GA and Tsezou A: Epigenetic regulation of hTERT promoter in hepatocellular carcinomas. Int J Oncol 34: 391-399, 2009.
2. Vente MA, Wondergem M, van der Tweel I, van den Bosch MA, Zonnenberg BA, Lam MG, van Het Schip Ad and Nijsen JF: Yttrium-90 microsphere radioembolization for the treatment of liver malignancies: A structured meta-analysis. Eur Radiol 19: 951-959, 2009.

3. Wong PY, Xia V, Imagawa DK, Hoefs J and Hu KQ: Clinical presentation of hepatocellular carcinoma (HCC) in AsianAmericans versus non-Asian-Americans. J Immigr Minor Health 13: 842-848, 2011

4. El-Serag HB: Hepatocellular carcinoma. N Engl J Med 365: 1118-1127, 2011.

5. Chen CJ, Yang HI, Su J, Jen CL, You SL, Huang GT and Iloeje UH; REVEAL-HBV Study Group: Risk of hepatocellular carcinoma across a biological gradient of serum hepatitis B virus DNA level. JAMA 295: 65-73, 2006.

6. Huo LF, Tang JW, Huang JJ, Huang PT, Huang CF, Kung HF and Lin MC: Cancer immunotherapy targeting the telomerase reverse transcriptase. Cell Mol Immunol 3: 1-11, 2006.

7. Mizukoshi E, Nakamoto Y, Marukawa Y, Arai K, Yamashita T, Tsuji H, Kuzushima K, Takiguchi M and Kaneko S: Cytotoxic $\mathrm{T}$ cell responses to human telomerase reverse transcriptase in patients with hepatocellular carcinoma. Hepatology 43: 1284-1294, 2006.

8. Wu KJ, Grandori C, Amacker M, Simon-Vermot N, Polack A, Lingner J and Dalla-Favera R: Direct activation of TERT transcription by c-MYC. Nat Genet 21: 220-224, 1999.

9. Saini N, Srinivasan R, Chawla Y, Sharma S, Chakraborti A and Rajwanshi A: Telomerase activity, telomere length and human telomerase reverse transcriptase expression in hepatocellular carcinoma is independent of hepatitis virus status. Liver Int 29: 1162-1170, 2009.

10. Li JH, Liu Y, Wang HF, et al: Construction of hTERT promoter-driven TRAIL expression vector and its inhibitory effects on hepatoma cell proliferation. Journal of Jilin University (medicine edition) 36: 825-831, 2010 (In Chinese).

11. Yang YJ, Chen H, Huang P, Li CH, Dong ZH and Hou YL: Quantification of plasma hTERT DNA in hepatocellular carcinoma patients by quantitative fluorescent polymerase chain reaction. Clin Invest Med 34: E238, 2011.

12. Qian Y, Yang L and Cao S: Telomeres and telomerase in T cells of tumor immunity. Cell Immunol 289: 63-69, 2014.

13. Tabori U, Ma J, Carter M, Zielenska M, Rutka J, Bouffet E, Malkin D and Hawkins C: Human telomere reverse transcriptase expression predicts progression and survival in pediatric intracranial ependymoma. J Clin Oncol 24: 1522-1528, 2006.

14. Edmondson HA and Steiner PE: Primary carcinoma of the liver: A study of 100 cases among 48,900 necropsies. Cancer 7: 462-503, 1954.

15. Takahashi S, Kitamoto M, Takaishi H, Aikata H, Kawakami Y, Nakanishi T, Shimamoto F, Tahara E, Tahara H, Ide T, et al: Expression of telomerase component genes in hepatocellular carcinomas. Eur J Cancer 36: 496-502, 2000

16. Zhang PH, Zou L and Tu ZG: RNAi-hTERT inhibition hepatocellular carcinoma cell proliferation via decreasing telomerase activity. J Surg Res 131: 143-149, 2006.

17. Miura N, Osaki Y, Nagashima M, Kohno M, Yorozu K, Shomori K, Kanbe T, Oyama K, Kishimoto Y, Maruyama S, et al: A novel biomarker TERTmRNA is applicable for early detection of hepatoma. BMC Gastroenterol 10: 46, 2010.

18. Lanson NA Jr, Friedlander PL, Schwarzenberger P, Kolls JK and Wang G: Replication of an adenoviral vector controlled by the human telomerase reverse transcriptase promoter causes tumor-selective tumor lysis. Cancer Res 63: 7939-7941, 2003.

19. Toshikuni N, Nouso K, Higashi T, Nakatsukasa H, Onishi T, Kaneyoshi T, Kobayashi Y, Kariyama K, Yamamoto K, Tsuji T, et al: Expression of telomerase associated protein 1 and telomerase transcriptase in hepatocellular carcinoma. Br J Cancer 82: 833-837, 2000. 